\title{
Visual search proceeds concurrently during the attentional blink and response selection bottleneck
}

\author{
Jongmin Lee ${ }^{1} \cdot$ Suk Won Han ${ }^{1}$ \\ Published online: 13 May 2020 \\ (C) The Psychonomic Society, Inc. 2020
}

\begin{abstract}
It is well known that human information processing comprises several distinct subprocesses - namely, the perceptual, central, and motor stage. In each stage, attention plays an important role. Specifically, a type of attention — perceptual attention —operates to detect and identify a sensory input. Following this, another class of attention — central attention - is involved in working memory encoding and response selection at the central stage. While perceptual attention and central attention are known to be separate, distinct processes, some researchers reported findings that loading central attention postponed the deployment of perceptual attention needed to perform a spatial configuration search. We tested whether a similar pattern of results would emerge when a different kind of search task is used. To do so, we had participants perform a visual-search task of searching for a feature conjunction target, taxing perceptual attention while they are engaged in central processes, such as working memory encoding and response selection. The results showed that perceptual processing of conjunction search stimuli could be carried out concurrently with central processes. These results suggest that the nature of the concurrent visual search process is a determinant responsible for the dynamic relationship between perceptual attention deployed for visual search and central attention needed for working memory encoding and response selection.
\end{abstract}

Keywords Working memory encoding $\cdot$ Response selection $\cdot$ Perceptual attention $\cdot$ Central attention

The human brain is constantly exposed to a huge amount of information. However, despite the impressive capability and complexity of the brain, the capacity of human information processing is severely limited. An illustrative example of such capacity limitation is the psychological refractory period (PRP) phenomenon. Specifically, under a dual-task setting, in which one tries to perform two sensory-motor tasks in rapid succession, the response to the second task is delayed (Welford, 1952).

\section{Public significance}

Human cognition involves separate, distinct processing stages, such as low level, perceptual stage and central, cognitive stage. The present study examined how these differential processes interact. We found that under certain circumstances, perceptual analysis of a stimulus can proceed simultaneously with a central process of another. These findings provided important insights regarding how human cognition is structured and how multitasking is possible.

Suk Won Han

suk.w.han@gmail.com

1 Department of Psychology, Chungnam National University, Daejeon, Republic of Korea
To explain the PRP, the central bottleneck model (Pashler, 1994) suggests that the performance of a sensory-motor task involves three distinct stages of processing - namely, perceptual, central, and motor (see Fig. 1). Specifically, at the perceptual stage, a sensory input is encoded and identified (Treisman \& Gelade, 1980), followed by the central stage at which response selection or short-term memory consolidation takes place (Jolicoeur \& Dell'Acqua, 1999). The selected response is executed at the motor stage. Importantly, unlike other stages, at the central stage, only a single response selection proceeds at a time (Pashler, 1994). Hence, when two sensory inputs are presented in rapid succession, the response selection of the second stimulus should be postponed until the response selection of the first is completed. This waiting period is referred to as the "slack" period (see Fig. 1). Although it is debated whether multiple response selections can proceed in parallel, it is commonly agreed that the PRP primarily originates from the central stage (Pashler, 1984, 1994; Tombu \& Jolicœur, 2003, 2005).

Another example demonstrating capacity limit at the central stage is the attentional blink (AB) phenomenon, which refers to impairment in identifying the second of two targets when the temporal interval between the two targets is within $200-500 \mathrm{~ms}$ 


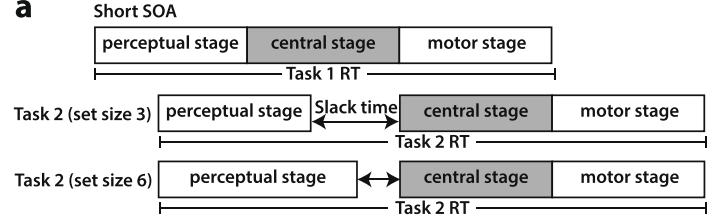

b Short SOA

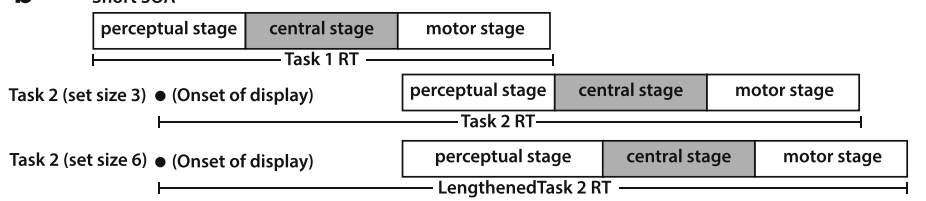

C

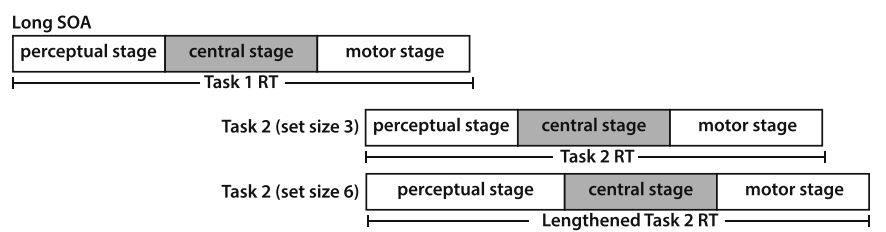

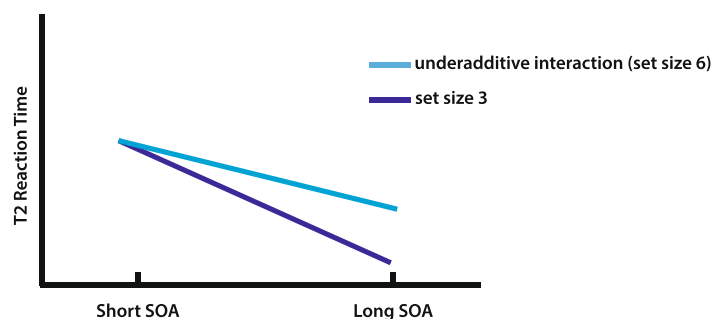

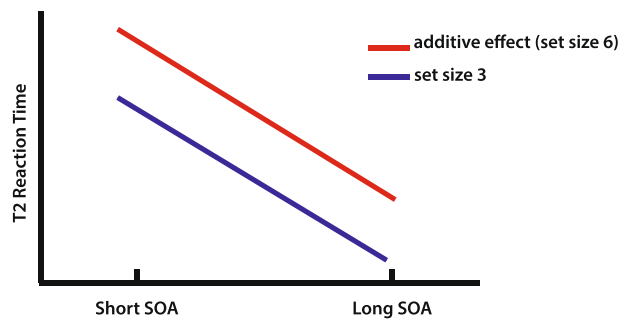

Fig. 1 Schematic depicting distinct processing stages and comparison of mechanism between underadditive interaction and additive effect. a Visual attention and central attention have a separate, independent capacity. At the short stimulus onset asynchrony (SOA), when the increased search set size increases the duration of the perceptual stage, the increased processing duration is absorbed into the slack time. Hence,

(Chun \& Potter, 1995; Raymond, Shapiro, \& Arnell, 1992). According to a bottleneck model of the AB (Chun \& Potter, 1995; Jolicoeur, 1998, 1999), while the first target (T1) is being encoded into working memory, the second target (T2) should wait to be encoded until T1 encoding is completed, which is why T2 is often missed when the T1-T2 interval is short. Jolicoeur and Dell'Acqua (1998) argued that working memory encoding, like response selection, requires capacity-limited attentional resources at the central stage.

The PRP and AB illustrate the capacity limit of central attention, but the capacity limit at the perceptual stage is mainly observed when one performs a visual-search task. A seminal study by Treisman and Gelade (1980) reported that when one searched for a target stimulus defined by a combination of two simple features, such as color, shape, or size, search performance suffered as the number of search items increased. This set-size effect was explained by positing limitations of attentional capacity. Specifically, to locate a conjunction target, it was suggested that attention should be serially allocated to each item due to the capacity-limited nature of visual attention (Treisman \& Gelade, 1980). Even though the interpretation that the presence of significant set-size effect is evidence for the capacity limit was challenged (Han, 2017b; Huang \& Pashler, 2005), recent studies reported that the performance of a conjunction search consumes capacity-limited attentional resources (Bouvier \& Treisman, 2010; Han, 2017b). underadditive interaction of SOA and set size on reaction time (RT) of Task 2 should arise. $\mathbf{b}$ Visual attention and central attention have shared a common capacity limitation. At the short SOA, when the search set size increases, an additive effect of SOA and set size on reaction time of Task 2 should arise. $\mathbf{c}$ Processing stages at the long SOA

These distinct forms of capacity limitations arising from distinct processing stages of cognition were claimed to have a differential functional role and nature (for a review, see Tamber-Rosenau \& Marois, 2016). Hence, they have been separately studied. However, recently, several groups of researchers (Han, 2017a; Reimer \& Schubert, 2019; Reimer, Strobach, Frensch, \& Schubert, 2015; Reimer, Strobach, \& Schubert, 2016) investigated the interplay of visual attention and central attention. In such a study, a dual-task paradigm consisting of a speeded-response selection task and a conjunction search task (Han, 2017a; see also Reimer et al., 2015) was employed. The first task (Task 1 [T1]) was a four-choice letter discrimination task, whereas the second task (Task 2 [T2]) was a visual-search task, in which the target was a $45^{\circ}$-tilted red Gabor grating among red vertical Gabor gratings and green $45^{\circ}$-tilted Gabor gratings. The number of search items was either three (Set Size 3) or six (Set Size 6). The stimulus onset asynchrony (SOA) between the two tasks was also manipulated, such that the T1 was followed by the T2 with either short (120 ms) or long (1,820 ms) SOA.

Under this locus of slack paradigm, an important aspect of the result is whether the manipulation of search reaction time (T2 RT) has a similar or different effect across the SOAs. Specifically, increasing set size from three to six should yield increased search RT at the long SOA. For short SOA, there are two possibilities. First, the magnitude of RT increase could be 
smaller for the short SOA than for the long SOA. This is because increased search time is absorbed into the slack period. Hence, this pattern of result would show a significant underadditive interaction between SOA and set size (see Fig. $1 \mathrm{a}, \mathrm{c}$ ). It can be argued that visual attention is not subject to the capacity limitation of central process. Second, the magnitude of set-size effect at the short SOA would be equivalent to that for the long SOA. In this case, there would not be a significant interaction between SOA and set size (Fig. 1b, c), implying that the visual search starts after the central stage of Task 1 . This additive effect of SOA and set size on T2 RT can be explained by positing that visual and central attention have shared a common pool of capacity limitation.

Based upon this paradigm, the results showed that at the long SOA, there was a significant and robust set-size effect, while at the short SOA, a drastically decreased set-size effect was found. This significant underadditive interaction of set size on T2 RT with SOA suggests that increased processing duration of $\mathrm{T} 2$ due to increased set size was absorbed into the slack period, implying that the conjunction search proceeds simultaneously with the process of response selection at the central stage of T1 (see Fig. 1a, c). This also naturally leads to the claim that central attention needed for response selection and visual attention deployed for conjunction search have a distinct and separate capacity.

However, other studies provided evidence challenging the independence between visual and central attention. Unlike the studies mentioned above, these studies investigated whether working memory encoding, another form of central processes, affects visual search (Ghorashi, Smilek, \& Di Lollo, 2007; Lagroix, Grubert, Spalek, Di Lollo, \& Eimer, 2015). In these studies, a dual-task paradigm, pairing a rapid serial visual presentation (RSVP) task with a visual-search task was used. Specifically, in the study of Ghorashi et al. (2007), the researchers had participants detect a target stimulus inserted in an RSVP of distractors (Task 1 [T1]) and perform a visualsearch task (Task 2 [T2]), in which the target was a rotated $T$ among rotated $L$ s. Participants were required to identify a white letter in the RSVP of black letters and to encode the target letter into working memory for later report. Following the RSVP task, the search display was presented. Participants were instructed to report the presence or absence of the search target stimulus. The important manipulation was the SOA between the target letter and the search display $(0,180, \&$ $720 \mathrm{~ms}$ ). Another important independent variable was set size (six or 12). The results showed that Task $2 \mathrm{RT}$ increased with the SOA decrement, and the significant set-size effect was found across the SOAs. Importantly, there was no significant interaction between SOA and set size. Based upon this additive effect of set size on search RT with SOA (see Fig. 1b, c), the authors claimed that perceptual processing of search stimuli could not be carried out while T1 is being encoded into working memory, challenging the separation between central attention needed for working memory encoding and visual attention deployed for $T / L$ search.

How can these conflicting results be reconciled? To clarify this discrepancy, we compared the experiments of Han (2017a) and Reimer et al. (2015) with that of Ghorashi et al. (2007). Each experiment used the dualtask paradigm to study the interaction between visual and central attention by manipulating SOA and set size. However, Han (2017a) and Reimer et al. (2015) used the speeded-response selection task as the first task, whereas Ghorashi et al. (2007) used the RSVP task as the first task. Given that both working memory encoding and response selection commonly take place in a capacitylimited central stage (Jolicoeur \& Dell'Acqua, 1999), we supposed that the $\mathrm{AB}$ and the PRP phenomena might interact similarly with a visual-search task. Furthermore, several studies show that both the AB and the PRP phenomena commonly originate from the capacity-limited central stage (Jolicoeur, 1998, 1999; Jolicoeur \& Dell'Acqua, 1998; Ruthruff \& Pashler, 2001).

Hence, we hypothesized that the different patterns of results between the experiments of Han (2017a) and Reimer et al. (2015) and that of Ghorashi et al. (2007) are due to difference in the second task (T2), visual-search task, rather than the first task (T1). Specifically, Han (2017a) used a conjunction search task as a second task, which is presumed to proceed in a limited parallel manner. Originally, Treisman and Gelade (1980) argued that conjunction search is done by serially examining each search item, based upon significant setsize effect (Treisman \& Gelade, 1980). However, significant set-size effect can also be explained by positing that multiple items are processed in parallel, consuming capacity-limited attentional resources; the more items, the less attentional resource each item receives, giving rise to similar magnitude of a set-size effect as serial search yields (Sung, 2008; Townsend, 1971, 1972).

In line with this, Sung (2008) and Bichot, Rossi, and Desimone (2005) provided evidence that parallel processing is possible for detecting a conjunction target. Specifically, Bichot and colleagues investigated V4 neurons in monkeys during the conjunction search task and analyzed featurerelated enhancement of neuronal components. In this experiment, they found that multiple stimuli with a target feature across the visual field were simultaneously processed. In addition, they suggested that this neuronal activity result is consistent with the results from the feature search task that proceeded in a parallel manner. By contrast, Ghorashi et al. (2007) used a spatial configuration search (Wolfe, 1998) as a second task. This search task is known to be performed via serial shifting of attention (Bricolo, Gianesini, Fanini, Bundesen, \& Chelazzi, 2002; Kwak, Dagenbach, \& Egeth, 1991; Wolfe, Cave, \& Franzel, 1989; Woodman \& Luck, 2003). 
In summary, there is mixed evidence regarding whether visual attention and central attention are independent or not. We hypothesized that these contradictory results between previous studies are due to the distinct nature of visual search task employed. Specifically, when multiple search stimuli are processed in a serial manner, visual search is not able to proceed concurrently with central attention. By contrast, when multiple search stimuli are processed in parallel, visual search is able to proceed concurrently with central processing. To test this hypothesis, in the first experiment, we used the attentional blink dual-task paradigm, consisting of the RSVP task (Task 1) and the conjunction search task (Task 2). In the second, we used the PRP dual-task paradigm (Han, 2017a; Reimer et al., 2015), consisting of a speeded response selection task (Task 1) and the conjunction search task (Task 2) identical to Task 2 of the first experiment. In the third, we used the same paradigm with the first experiment, replacing the conjunction search task with the spatial configuration search task. To investigate the interaction between central attention needed for Task 1 and visual attention deployed for Task 2, we manipulated the SOA between Task 1 and Task 2 and search set size.

To predict results, if perceptual processing for conjunction stimuli proceeds during the capacity-limited central stage, there should be a significant underadditive interaction between SOA and set size. Namely, at the short SOA, the increased processing duration of visual attention on search stimuli should be absorbed into slack time evoked by the concurrent process of working memory encoding or response selection. At the long SOA, the increased processing duration of visual attention on search stimuli adds to Task 2 RT. Hence, the magnitude of set-size effect should be larger at the long SOA than at the short SOA. By contrast, if perceptual processing for conjunction stimuli cannot proceed during the capacity-limited central stage, there should be a similar pattern of result to Ghorashi et al. (2007). That is, increasing search set size has an additive effect on search RT with SOA.

\section{Experiment 1}

\section{Method}

\section{Participants}

Thirty-two adults (13 males, 18-25 years old) with normal or corrected-to-normal vision participated for course credit. To determine the sample size, we ran a power analysis using a data set included in a published study (Han, 2017a). It was estimated that an $N$ of 14 should be sufficient to detect a significant underadditive interaction between two factors of interest at the level of .80. Given the difference between the present and the previous study, we decided to double the sample size. We ended up collecting data from 32 people due to scheduling issues. The study was approved by the Institutional Review Broad (IRB) at Chungnam National University, and all participants gave written informed consent.

\section{Stimuli and apparatus}

The experiment was programmed and run using PsychoPy2 (Peirce, 2007). The stimuli were presented on a 20 -in. LCD monitor with a gray background. Participants performed a dual-task paradigm, consisting of a letter identification task and a conjunction search task. The first task started with the presentation of a white fixation $\operatorname{dot}\left(0.2^{\circ} \times 0.2^{\circ}\right.$ of visual angle) followed by a rapid serial visual presentation (RSVP) of digits and a letter $\left(0.6^{\circ} \times 0.6^{\circ}\right)$. Participants were to identify a letter (Target 1 [T1]) embedded in the RSVP, which ended by the symbol "\#” as a T1 mask (Bae, Jung, \& Han, 2018). The second task was a conjunction search task. The target (Target 2 [T2]) was a $T$ stimulus rotated $90^{\circ}$ to the right or left $\left(1.2^{\circ} \times 1.2^{\circ}\right)$. The target was accompanied by two or five distractors. The distractors were either green circles or red $90^{\circ}$ rotated $T \mathrm{~s}$. The search target and distractors were presented on an imaginary circle, whose radius was $3^{\circ}$.

\section{Design and procedure}

As shown in Fig. 2, a trial started with the 500-ms presentation of the fixation dot, followed by the RSVP. Participants were required to identify and maintain a target (Target 1 [T1]) for later report. On each trial, this T1 letter was one of the eight letters ("B," "F," "G," "H," "K," "X," "M," and "R"). The number of frames in the RSVP was randomly selected from six to nine, and the $\mathrm{T} 1$ position was one of the fifth, sixth, seventh, or eighth frame. The last frame was always the T1 mask ("\#”). Each frame lasted for $100 \mathrm{~ms}$.

Following the RSVP, a conjunction search task was presented. The SOA between the onset of $\mathrm{T} 1$ and the search display was either $200-\mathrm{ms}$ or $1,200-\mathrm{ms}$. In the conjunction search task, the target (Target 2 [T2]) was a $90^{\circ}$ rotated green $T$, and distractors were a $90^{\circ}$ rotated red $T$ and green outline circle. The search display contained either three or six items, presented for 250-ms. For this search task, participants looked for the target and indicated whether the bottom of the $T$ was pointed to the left or to the right by pressing the " $F$ " key (left) or the " $\mathrm{H}$ " key (right) on the keyboard. They were instructed to respond as fast and accurately as possible. Upon completing a response to $\mathrm{T} 2$, a prompt was displayed on the screen for $\mathrm{T} 1$ response. The T1 identity was reported by pressing corresponding keys on the keyboard ("1,, "2," "3," " 4, , "7,, " 8 ," "9," "0").

To sum up, the experimental design consisted of a $2 \times 2$ factorial design with SOA (short, long) and set size (three, six) as within-subject factors. There were one practice block and 


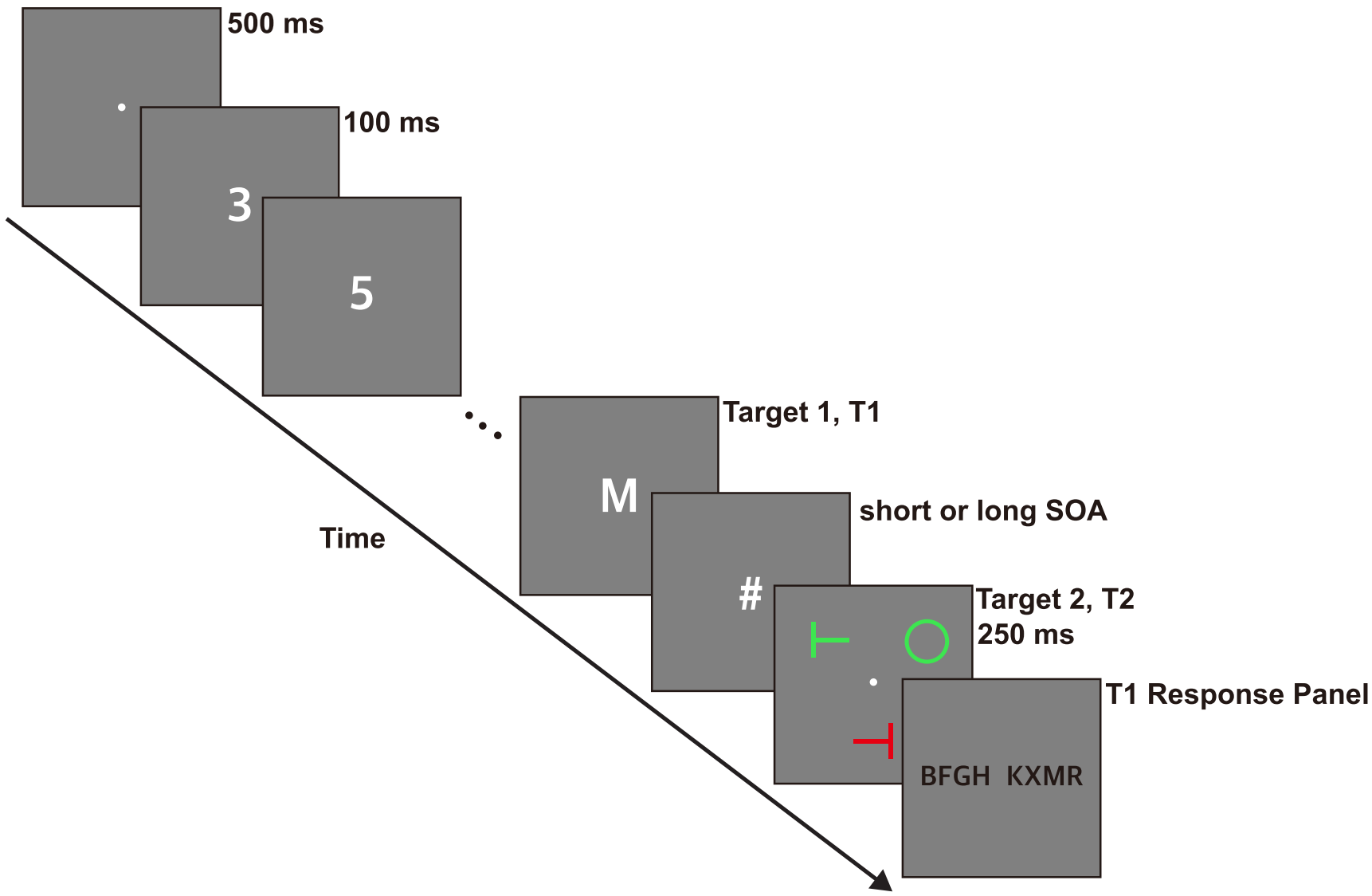

Fig. 2 Trial design of Experiment 1. A short stimulus onset asynchrony (SOA) and Set Size 3 trial is depicted

five experimental blocks, each of which was made up of 96 trials.

\section{Results and discussion}

Mean accuracies of the $\mathrm{T} 1$ and $\mathrm{T} 2$ responses were $92 \%$ and $96 \%$, respectively (see Table 1). A two-way repeated-measures analysis of variance (ANOVA) with SOA (short, long) and set size (three, six) as factors was applied to T1 and T2 accuracy data. This analysis revealed that there was a significant main effect of SOA on T1 accuracy, $F(1,31)=13.59$, $p$

Table 1 Accuracy (\%) data for Experiment 1

\begin{tabular}{llllll}
\hline & \multicolumn{3}{c}{ Early frame } & & Late frame \\
\cline { 2 - 3 } \cline { 5 - 6 } & Set Size 3 & Set Size 6 & & Set Size 3 & Set Size 6 \\
\hline Task 1 & & & & \\
Short SOA & $90.0(1.4)$ & $90.0(1.6)$ & & $91.3(1.5)$ & $90.8(1.4)$ \\
Long SOA & $92.3(1.3)$ & $91.9(1.4)$ & & $93.0(0.9)$ & $92.8(1.3)$ \\
Task 2 & & & & \\
Short SOA & $95.7(0.9)$ & $94.4(1.0)$ & & $96.2(0.8)$ & $95.7(0.9)$ \\
Long SOA & $97.1(0.8)$ & $96.3(0.8)$ & & $97.3(0.6)$ & $96.0(0.9)$ \\
\hline
\end{tabular}

Note. Standard error in parentheses. SOA = stimulus onset asynchrony
$<.001, \eta_{\mathrm{p}}{ }^{2}=.30$. Neither the main effect of set size nor the interaction between SOA and set size was significant $(p \mathrm{~s}>$ .59). The analysis for $T 2$ accuracy revealed a significant main effect of SOA, $F(1,31)=8.93, p<.01, \eta_{\mathrm{p}}{ }^{2}=.22$. The main effect of set size was also significant, $F(1,31)=6.00, p<.05$, $\eta_{\mathrm{p}}{ }^{2}=.16$. The interaction between SOA and set size was not significant, $F(1,31)=.03, p>.86$. These accuracy results ensure that subsequent RT data analyses would not be confounded by speed-accuracy trade-offs.

To analyze T2 RT data, we applied the same analysis (see Fig. 3). Importantly, only trials in which the $\mathrm{T} 1$ and $\mathrm{T} 2 \mathrm{re}-$ sponses were correct were analyzed. This analysis revealed that there was a significant main effect of SOA, $F(1,31)=$ $56.41, p<.001, \eta_{\mathrm{p}}{ }^{2}=.65$. We also found a significant main effect of set size, $F(1,31)=55.39, p<.001, \eta_{\mathrm{p}}{ }^{2}=.64$. The most important result is that the interaction between SOA and set size was significant, $F(1,31)=12.74, p<.01, \eta_{\mathrm{p}}{ }^{2}=.29$. To specifically investigate this interaction, we ran pairwise $t$ tests. These analyses showed that at the short SOA and long SOA, T2 RT was significantly greater for Set Size 6 trials than for Set Size 3 trials $(p s<.01)$. However, the magnitude of set-size effect was significantly smaller at the short SOA $(23 \mathrm{~ms})$ than at the long SOA (47 ms), $t(31)=3.57, p<.01$, Cohen's $d=$ 0.72 . These results indicate that increasing the set size had an underadditive effect on search RT with SOA. 


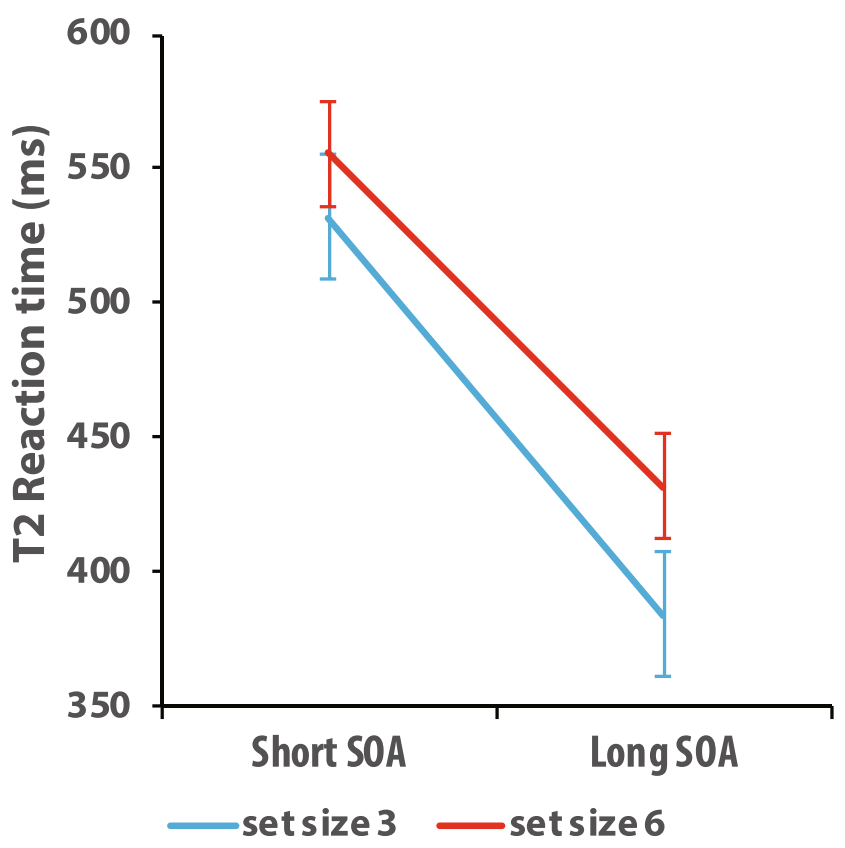

Fig. 3 Result of Experiment 1. Error bars represent within-subjects 95\% confidence intervals (Cousineau, 2005; Morey, 2008). SOA = stimulus onset asynchrony

Notably, an anonymous reviewer hypothesized that the serial position of T1 in the RSVP would affect the results. Hence, we investigated the T1 position-dependent performance. Originally, T1 was presented at one of the four positions of the RSVP. To improve the statistical power, we divided the data into two sets: the fifth frame and the sixth frame (early frame) versus the seventh frame and the eighth frame (late frame). A three-way ANOVA with SOA, set size, and T1 position as within-subject factors was applied to $\mathrm{T} 1$ and $\mathrm{T} 2$ accuracy data. Mean accuracy of T1 and T2 is summarized in Table 1. This analysis revealed that there was a significant main effect of SOA, $F(1,31)=13.58, p<.001, \eta_{\mathrm{p}}{ }^{2}=.30$, and T1 position on T1 accuracy, $F(1,31)=6.70, p<.05$, $\eta_{\mathrm{p}}{ }^{2}=.18$. None of the other main effects or interactions were significant $(p \mathrm{~s}>.59)$. The analysis for $\mathrm{T} 2$ accuracy revealed a significant main effect of SOA, $F(1,31)=9.22, p<.01$, $\eta_{\mathrm{p}}{ }^{2}=.23$, and set size, $F(1,31)=5.93, p<.05, \eta_{\mathrm{p}}{ }^{2}=.16$. None of the other main effects or interactions were significant ( $p \mathrm{~s}>.12$ ). These accuracy results ensure that subsequent RT data analyses would not be confounded by speed-accuracy trade-offs.

For T2 RT data, the same analysis revealed a significant main effect of SOA, $F(1,31)=56.60, p<.001, \eta_{\mathrm{p}}{ }^{2}=.65$, and set size, $F(1,31)=56.19, p<.001, \eta_{\mathrm{p}}{ }^{2}=.65$. The interaction between SOA and set size was significant, $F(1,31)=12.53$, $p<.01, \eta_{\mathrm{p}}{ }^{2}=.29$. Finally, there was a significant three-way interaction, $F(1,31)=5.43, p<.05, \eta_{\mathrm{p}}^{2}=.15$. To specifically examine the significant three-way interaction, we separately applied two-way ANOVAs for each frame, with SOA and set size as factors. At the early frame of the RSVP, there was a significant main effect of SOA, $F(1,31)=61.19, p<.001$, $\eta_{\mathrm{p}}{ }^{2}=.66$, and set size, $F(1,31)=41.23, p<.001, \eta_{\mathrm{p}}{ }^{2}=.57$. The interaction between SOA and set size was not significant $(p=.44)$. This result implied that SOA and set size yielded an additive effect on search RT (see Fig. 4a). At the late frame of the RSVP, there was a significant main effect of SOA, $F(1$, $31)=47.97, p<.001, \eta_{\mathrm{p}}{ }^{2}=.61$, and set size, $F(1,31)=23.11$, $p<.001, \eta_{\mathrm{p}}{ }^{2}=.43$, The interaction between SOA and set size was significant, $F(1,31)=16.85, p<.001, \eta_{\mathrm{p}}{ }^{2}=.35$. To specifically investigate this interaction, we ran pairwise $t$-tests. These analyses showed that there was no significant set-size effect at the short SOA ( $9 \mathrm{~ms}, p=.29)$, whereas there was a significant set-size effect at the long SOA $(49 \mathrm{~ms}), t(31)=$ $7.47, p<.001$, Cohen's $d=0.41$. These results indicate that increasing the set size had an underadditive effect on search RT with SOA (see Fig. 4b).

When we analyzed T2 RT data applying two-way ANOVA with SOA and set size as factors, as we predicted, there was a significant underadditive interaction implying that increasing set size in conjunction display (T2) yielded smaller effect on search RT at the short SOA than at the long SOA. This underadditive effect on search RT with SOA results is because in a dual-task situation, increased perceptual processing duration of conjunction search task due to increased search stimuli was absorbed into slack time evoked by concurrent central processing. Hence, we suggest that perceptual processing of conjunction search proceeds concurrently with the process of encoding T1 into working memory, which is taking place at the capacity-limited central stage.

Importantly, however, simultaneous processing of visual search and T1 encoding took place only when the T1 was presented at the relatively late position in the RSVP. This result suggests that attentional preparation (Holcombe, Kanwisher, \& Treisman, 2001) for the T1 is important to configure the system for the upcoming visual search task. Related to this, Ariga and Yokosawa (2008) reported that attention should be awakened for optimal target processing in the RSVP. They found that target accuracy was greater when the target was placed at later positions of an RSVP than at earlier positions. Consistent with this, we also found that $\mathrm{T} 1$ performance was significantly greater at the late frame than at the early frame, $t(31)=2.59, p<.05$, Cohen's $d=0.12$. Furthermore, our results suggest that when the system is well prepared for $\mathrm{T} 1$, the subsequent search process is also able to be carried out simultaneously with $\mathrm{T} 1$ encoding.

\section{Experiment 2}

Experiment 1 showed that while a target stimulus (T1) is being encoded into working memory, perceptual processing of searching for another target (T2) took place. In Experiment 2, we examined whether the process of response selection for $\mathrm{T} 1$ 
a

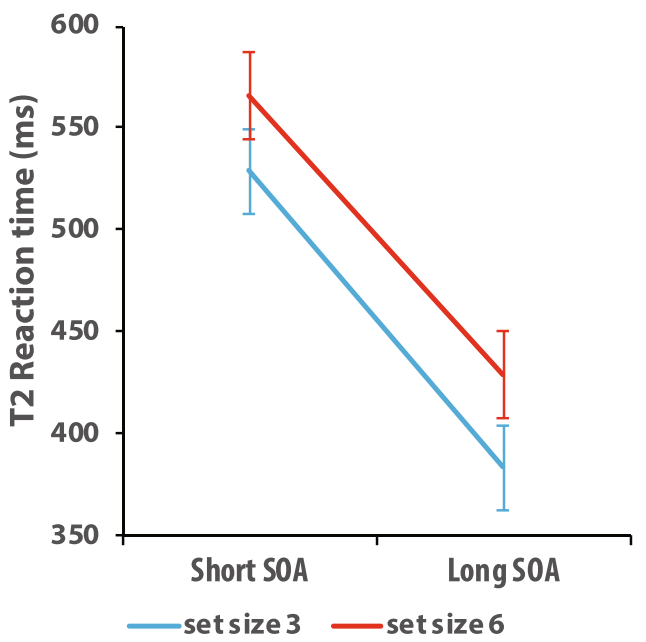

Fig. 4 Result of Experiment 1. a When the T1 was presented at the early frame of the rapid serial visual presentation (RSVP), there was an additive effect of set size with stimulus onset asynchrony (SOA) on T2 RT. b When the T1 was presented at the late frame of the RSVP, there was a

could also be done simultaneously with perceptual processing for T2. Indeed, recent studies found that response selection and perceptual process of visual search stimuli could be done in parallel (Han, 2017a; Reimer \& Schubert, 2019; Reimer et al., 2015; Reimer et al., 2016). By replicating the previous results with the present visual search task, we can further validate the findings of Experiment 1.

\section{Method}

\section{Participants}

Eighteen adults (10 males, 18-25 years old) with normal or corrected-to-normal vision participated for course credit. To be noted, this experiment is a replication of our previous finding with a slight modification (Han, 2017a). Hence, we reasoned that an $N$ of 14 should be sufficient to detect a significant underadditive interaction between two factors of interest at the level of .80. The study was approved by the Institutional Review Broad (IRB) at Chungnam National University, and all participants gave written informed consent.

\section{Stimuli and apparatus}

The stimuli and apparatus were identical to those of Experiment 1, except for the following. The first task (Target $1[\mathrm{~T} 1]$ ) was a letter identification task and the T1 was Korean letters, “가," “나," “다,” or “라” (Han, 2017a). Participants were required to make an immediate and speeded response to the T1. The letters were written in black and presented at center of the screen. The height of letters was $1^{\circ}$ of visual angle. b

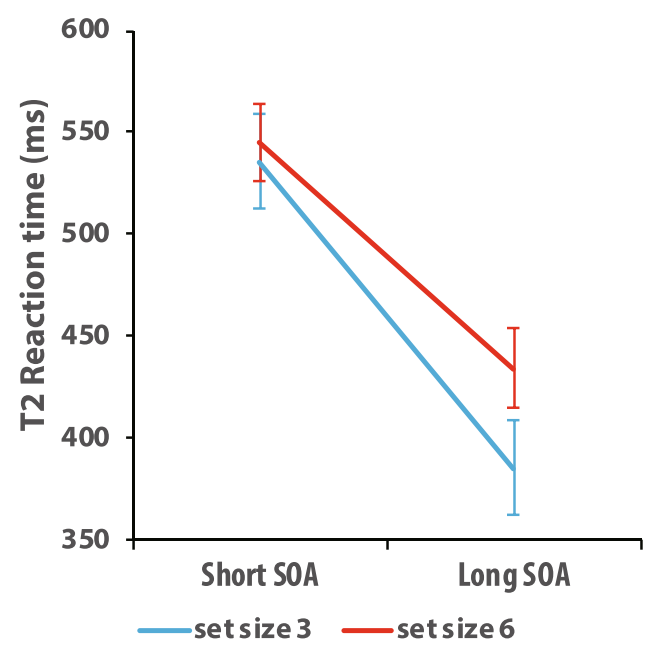

significant underadditive interaction between SOA and set size. Error bars represent within-subjects 95\% confidence intervals (Cousineau, 2005; Morey, 2008)

\section{Design and procedure}

The details were identical to those of Experiment 1, except for the following. As shown in Fig. 5, T1 stimulus was presented for $100 \mathrm{~ms}$, followed by the 250-ms T2 stimulus presentation. The SOA between the onset of $\mathrm{T} 1$ and the search display was either $220 \mathrm{~ms}$ or $1,300 \mathrm{~ms}$. Participants responded to one of four different Korean letters, "가," "나," “다," or "라” by pressing corresponding keys on the keyboard ("Z," "X," "C," or "V") with their left hand. T2 was responded by pressing the "." key (left) or the " " key (right) on the keyboard with their right hand. Participants were instructed to perform the two tasks as fast and accurately as possible. To sum up, the experimental design consisted of a $2 \times 2$ factorial design with SOA (short, long) and set size (three, six) as within-subject factors. There were one practice block and five experimental blocks, each of which was made up of 96 trials.

\section{Results and discussion}

Mean accuracies of the $\mathrm{T} 1$ and $\mathrm{T} 2$ responses were $95 \%$ and $94 \%$, respectively (see Table 2). A two-way repeated-measures ANOVA with SOA (short, long) and set size (three, six) as factors was applied to T1 and T2 accuracy data. These analyses revealed that there was a significant main effect of SOA on T1 accuracy, $F(1,17)=5.76, p<.05, \eta_{\mathrm{p}}{ }^{2}=$ .25 . The main effect of set size and the interaction between SOA and set size were not significant $(p s>.20)$. The analysis for T2 accuracy revealed a significant main effect of SOA, $F(1,17)=44.48, p<.001, \eta_{\mathrm{p}}^{2}=.72$. The main effect of set size and the interaction between SOA and set size was not significant $(p \mathrm{~s}>.62)$. These accuracy analysis results 


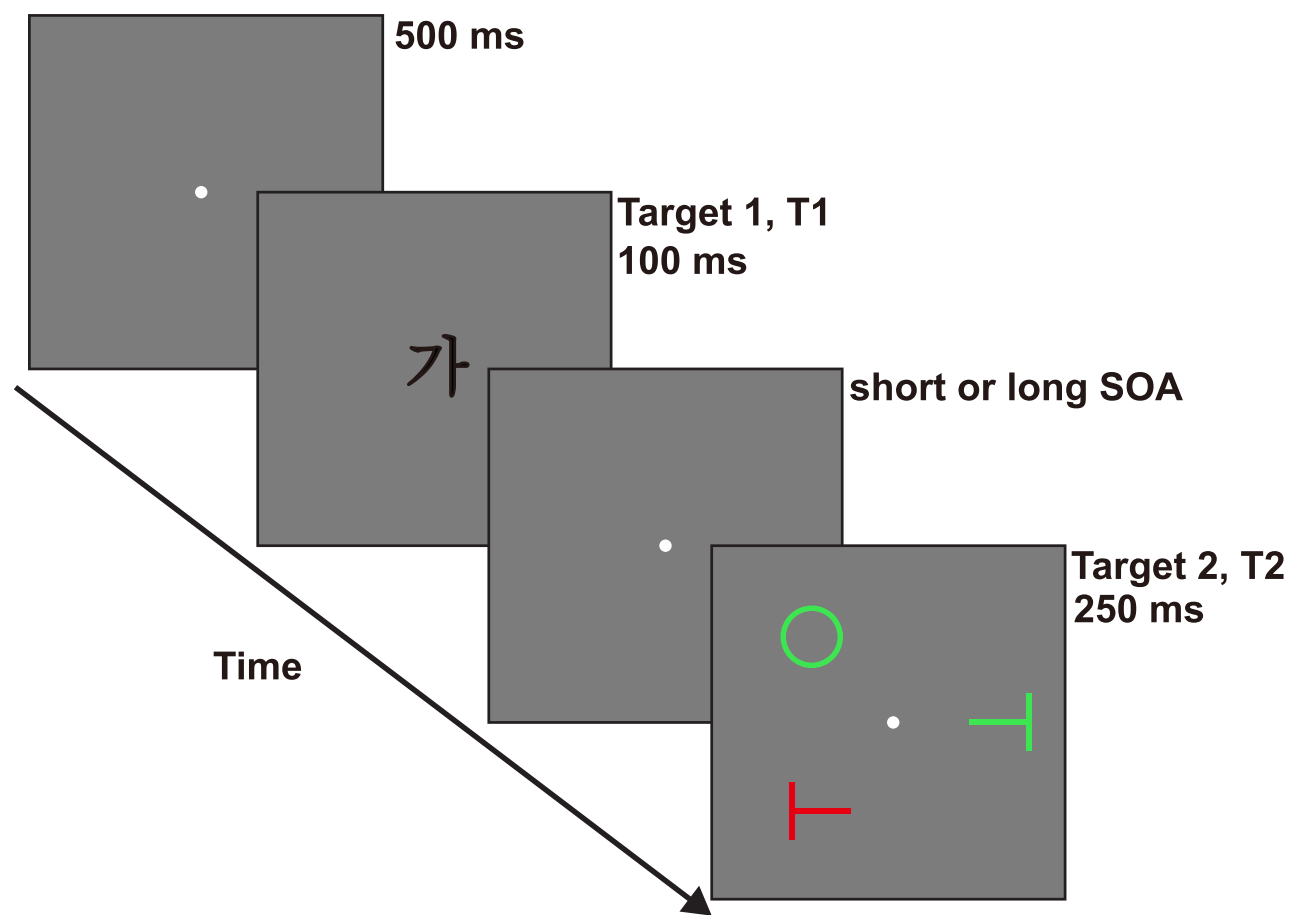

Fig. 5 Trial design of Experiment 2. A short stimulus onset asynchrony (SOA) and Set Size 3 trial is depicted

guarantee that subsequent RT data analyses would not be confounded by speed-accuracy trade-offs.

The T2 RT data were analyzed in the same way as Experiment 1 (see Fig. 6). Importantly, only trials in which the $\mathrm{T} 1$ and $\mathrm{T} 2$ responses were correct were analyzed. As results, the main effect of set size was significant, $F(1,17)=$ $70.15, \mathrm{p}<.001, \eta_{\mathrm{p}}{ }^{2}=.80$, and so was the main effect of SOA, $F(1,17)=113.60, p<.001, \eta_{\mathrm{p}}{ }^{2}=.87$. Importantly, the interaction between SOA and set size was also significant, $F(1,17)$ $=34.49, p<.001, \eta_{\mathrm{p}}{ }^{2}=.67$. Subsequent pairwise $t$ tests showed that at the short SOA and long SOA, T2 RT was significantly greater for Set Size 6 trials than Set Size 3 trials $(p \mathrm{~s}<.01)$. However, the magnitude of set-size effect was significantly smaller at the short SOA $(16 \mathrm{~ms})$ than at the long SOA (45 ms), $t(17)=5.87, p<.001$, Cohen's $d=1.57$, consistent with the results of Experiment 1 and other previous studies (Han, 2017a; Reimer et al., 2015).

Table 2 Accuracy (\%) data for Experiment 2

\begin{tabular}{lcc}
\hline & Set Size 3 & Set Size 6 \\
\hline Task 1 & & \\
Short SOA & $94.3(1.3)$ & $93.2(1.5)$ \\
Long SOA & $96.3(0.6)$ & $96.2(1.0)$ \\
Task 2 & & $92.1(0.6)$ \\
Short SOA & $92.0(0.5)$ & $95.9(0.4)$ \\
Long SOA & $96.2(0.5)$ & \\
\hline
\end{tabular}

Note. Standard error in parentheses. SOA = stimulus onset asynchrony
For T1 RT data, we also applied the same analysis. There was a significant main effect of SOA, $F(1,17)=31.64, p<$ $.001, \eta_{\mathrm{p}}{ }^{2}=.65$, and set size, $F(1,17)=6.53, p<.05, \eta_{\mathrm{p}}{ }^{2}=.28$. The interaction between SOA and set size was also significant, $F(1,17)=6.26, p<.05, \eta_{\mathrm{p}}{ }^{2}=.27$. Subsequent pairwise $t$ tests showed that there was a significant T1 RT increment as set size of T2 increases at the short SOA $(17 \mathrm{~ms}), t(17)=2.75, p<$

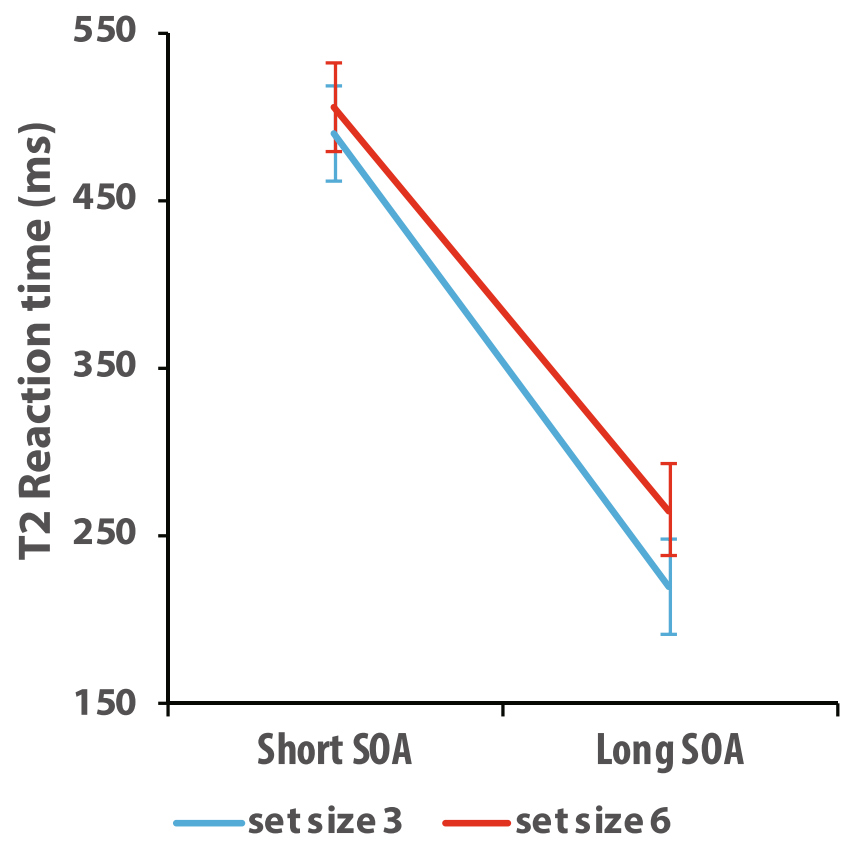

Fig. 6 Result of Experiment 2. Error bars represent within-subjects 95\% confidence intervals (Cousineau, 2005; Morey, 2008). SOA = stimulus onset asynchrony 
.05 , Cohen's $d=0.11$. However, there was no significant T1 RT increment at the long SOA $(p=.37)$. The significant main effect of SOA indicates that response to the T1 was slower at the short SOA than at the long SOA (63 ms vs. $52 \mathrm{~ms})$. This T1 RT slowing was also observed in other studies (Brisson \& Jolicoeur, 2007a; Han, 2017a; Tombu \& Jolicœur, 2003). Although there could be several reasons why T1 RT is affected by T2 demand (Han \& Marois, 2013; Tombu \& Jolicœur, 2003), importantly, this finding does not challenge the claim that response selection for $\mathrm{T} 1$ is carried out simultaneously with the following visual search.

Taken together, we found a significant underadditive interaction between SOA and set on T2 RT, consistent with the results from Experiment 1. This is a replication of previous studies (Han, 2017a; Reimer \& Schubert, 2019; Reimer et al., 2015; Reimer et al., 2016) showing that perceptual processing of conjunction search took place during the response selection bottleneck. Accordingly, our result confirms that when multiple search items are processed in a limited parallel manner, the perceptual processing of search task can be performed simultaneously with central processes, such as working memory encoding and response selection.

\section{Experiment 3}

Experiments 1 and 2 showed that when visual search is performed in a limited parallel manner, processing of multiple search stimuli is done simultaneously with working memory encoding and response selection. Furthermore, in Experiment 1 , we found that the interplay of working memory encoding and search performance is modulated by the $\mathrm{T} 1$ position. In Experiment 3, to confirm our hypothesis and replicate the study of Ghorashi et al. (2007), we also used the AB paradigm, but replaced the conjunction search task with the spatial configuration search task, which is known to be performed via serial shifting of attention. Hence, we predicted that increasing the set size yields an additive effect on search RT with SOA, regardless of when the serial position of T1 in the RSVP.

\section{Method}

\section{Participants}

Nineteen adults (nine males, $18-25$ years old) with normal or corrected-to-normal vision participated for course credit. To determine the sample size, we ran a power analysis using a data set included in Experiment 1. It was estimated that an $N$ of 18 should be sufficient to detect a significant underadditive interaction between two factors of interest at the level of .80 . The study was approved by the Institutional Review Broad (IRB) at Chungnam National University, and all participants gave written informed consent.

\section{Stimuli and apparatus}

The stimuli and apparatus were identical to those of Experiment 1, except that search display contained a $90^{\circ}$ rotated green $T$ and $90^{\circ}$ rotated green $L$ s. To increase the demand for serial search, we added offset at the junction of two lines of the $L$ s (see Fig. 7).

\section{Design and procedure}

The details were identical to those of Experiment 1, except for the following. As shown in Fig. 7, following the RSVP, a spatial configuration search task was presented. In the spatial configuration search task, the target was a $90^{\circ}$ rotated green $T$ and distractors were $90^{\circ}$ rotated green $L$ s.

For this search task, participants looked for the target and indicated whether the bottom of the $T$ was pointed to the left or to the right by pressing the "F" key (left) or the "H" key (right) on the keyboard.

To sum up, the experimental design consisted of a $2 \times 2 \times 2$ factorial design with SOA (short, long), set size (three, six), and $\mathrm{T} 1$ position (early, late) as within-subject factors. There were one practice block and five experimental blocks, each of which was made up of 96 trials.

\section{Results and discussion}

Mean accuracies of the T1 and T2 responses were 92\% and $90 \%$, respectively (see Table 3 ). A three-way repeated-measures ANOVA with SOA (short, long), set size (three, six), and $\mathrm{T} 1$ position (early frame, late frame) as within-subject factors was applied to T1 and T2 accuracy data. For T1 accuracy data, there was a significant main effect of SOA, $F(1,18)$ $=27.87, p<.001, \eta_{\mathrm{p}}{ }^{2}=.61$, and $\mathrm{T} 1$ position, $F(1,18)=21.63$, $p<.001, \eta_{\mathrm{p}}{ }^{2}=.55$. The two-way interaction between SOA and $\mathrm{T} 1$ position was significant, $F(1,18)=4.48, p<.5, \eta_{\mathrm{p}}{ }^{2}=$ .20. None of the other main effects or interactions were significant $(p s>.59)$. Finally, to specifically investigate the main effect of T1 position, we ran a pairwise $t$ test. This analysis revealed that the $\mathrm{T} 1$ performance was significantly greater at the late frame (93\%) than at the early frame $(91 \%), t(18)=$ $4.65, p<.001$, Cohen's $d=0.32$, indicating that the attentional awakening phenomenon arose. For T2 accuracy data, there was a significant main effect of SOA, $F(1,18)=9.58, p<$ $.01, \eta_{\mathrm{p}}{ }^{2}=.35$, and set size, $F(1,18)=64.24, p<.001, \eta_{\mathrm{p}}{ }^{2}=$ .78. None of the other main effects of interactions were significant $(p s>.12)$.

For T2 RT data, we calculated an adjusted RT (inverse efficiency) by dividing the T2 RT data by the T2 accuracy data because of the significant main effect of set size on T2 accuracy (Graham et al., 2006; Han \& Marois, 2013; Klemen, Verbruggen, Skelton, \& Chambers, 2011; Romei, Driver, Schyns, \& Thut, 2011; Spence, Kettenmann, Kobal, \& 


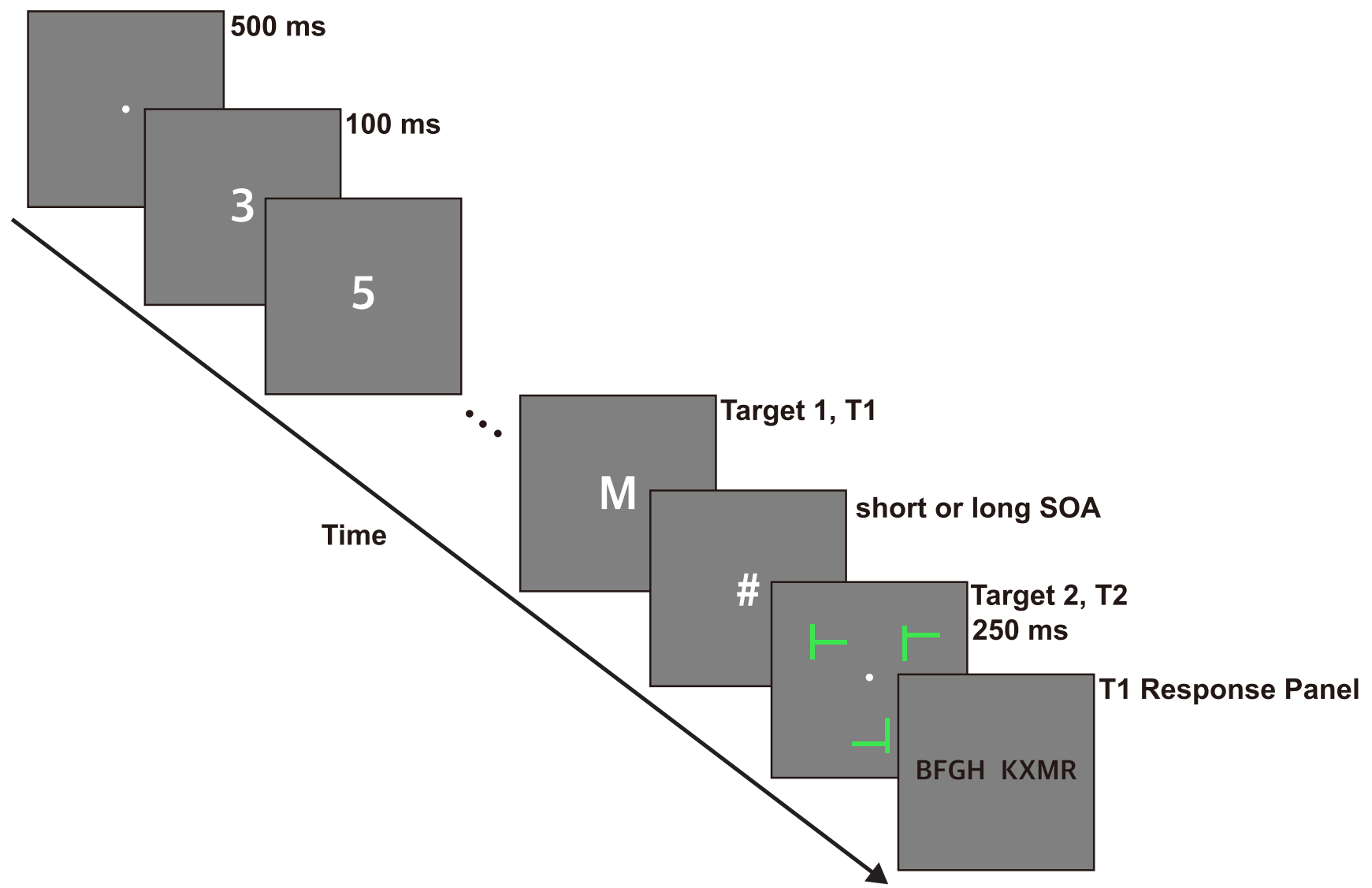

Fig. 7 Trial design of Experiment 3. A short stimulus onset asynchrony (SOA) and Set Size 3 trial is depicted

McGlone, 2001; Townsend \& Ashby, 1983). For the adjusted T2 RT data, we applied the three-way repeated-measures ANOVA with SOA (short, long), set size (three, six), and T1 position (early frame, late frame) as within-subject factors. Importantly, only trials in which the $\mathrm{T} 1$ and $\mathrm{T} 2$ responses were correct were analyzed. This analysis revealed a significant main effect of SOA, $F(1,18)=79.33, p<.001, \eta_{\mathrm{p}}{ }^{2}=.82$, and set size, $F(1,18)=124, p<.001, \eta_{\mathrm{p}}{ }^{2}=.87$. Importantly, there was no significant two-way interaction between SOA and set size $(p=.49)$. None of the other main effects or interactions were significant $(p s>.10)$. Despite nonsignificant

Table 3 Accuracy (\%) data for Experiment 3

\begin{tabular}{llllll}
\hline & \multicolumn{3}{c}{ Early frame } & & \multicolumn{2}{c}{ Late frame } \\
\cline { 2 - 3 } \cline { 6 - 6 } & Set Size 3 & Set Size 6 & & Set Size 3 & Set Size 6 \\
\hline Task 1 & & & & \\
Short SOA & $89.1(1.5)$ & $88.8(2.1)$ & & $92.3(1.1)$ & $91.8(1.5)$ \\
Long SOA & $92.9(1.2)$ & $92.5(1.4)$ & $94.0(1.2)$ & $93.4(1.2)$ \\
Task 2 & & & & \\
Short SOA & $94.6(1.1)$ & $83.3(2.1)$ & $95.9(1.1)$ & $84.2(1.8)$ \\
Long SOA & $96.6(0.7)$ & $86.8(1.7)$ & $96.1(0.8)$ & $86.1(2.0)$ \\
\hline
\end{tabular}

Note. Standard error in parentheses. SOA = stimulus onset asynchrony three-way interaction, we separately analyzed the adjusted T2 RT data depending on the T1 position to examine the attentional awakening effect on the search performance. The results showed that at the early and the late frame, there were significant main effects of SOA, $F_{\mathrm{S}}(1,18)>44.39, p \mathrm{~s}<.001$, $\eta_{\mathrm{p}}^{2}>.71$, and set size, $F_{\mathrm{S}}(1,18)>94.61, p \mathrm{~s}<.001, \eta_{\mathrm{p}}^{2}>.84$. Importantly, across the frames, the interactions between SOA and set size were not significant ( $p$ s $>.13$; see Fig. 8a, b).

As predicted, we found an additive effects of set size with SOA on search RT. These results indicate that increased processing duration as set size increases was performed after the central processing of $\mathrm{T} 1$ was finished, instead of being absorbed into the slack time at the short SOA. Based upon this, we suggest that the perceptual processing of spatial configuration stimuli is postponed until working memory encoding for T1 is completed. Hence, when visual search is performed in a serial manner, searching for a target could not be done simultaneously with the central processing of concurrent another task. These results are consistent with our hypothesis and the result from Ghorashi et al.'s (2007) study. Furthermore, the result that additive effect was found irrespective of the $\mathrm{T} 1$ position implies that even when the system was sufficiently prepared, the deployment of visual attention could not be carried out concurrently during working memory encoding. 


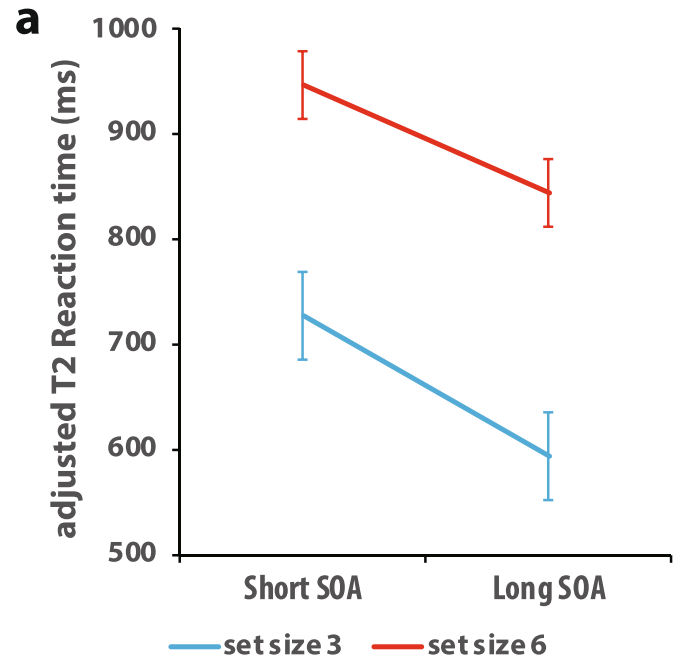

Fig. 8 Results of Experiment 3. a When the T1 was presented at the early frame of the rapid serial visual presentation (RSVP), there was an additive effect of set size with stimulus onset asynchrony (SOA) on adjusted T2 reaction time (RT). b When the T1 was presented at the late frame of the

Importantly, to convincingly claim that these contrasting results between Experiment 1 and Experiment 3 are caused by the different nature of search processes, we ran a four-way mixed ANOVA adding experiment (conjunction search of Experiment 1 vs. spatial configuration search of Experiment 3 ) as a between-subject factor. Notably, because we used the adjusted T2 RT data in Experiment 3, we used the adjusted T2 RT data from Experiment 1 as input data on ANOVA. The full results of the ANOVA are shown in Table 4. Most importantly, there was a significant four-way interaction. To specifically

Table 4 Four-way mixed ANOVA results for the adjusted T2 RT data of Experiments 1 and 3

\begin{tabular}{llll}
\hline Factors & $F$ & $p$ & $\eta_{\mathrm{p}}{ }^{2}$ \\
\hline SOA & 114.125 & $<.001$ & .70 \\
Set size & 162.300 & $<.001$ & .77 \\
T1 position & 2.733 & .105 & \\
Experiment & 30.11 & $<.001$ & .38 \\
SOA $\times$ Set Size & 5.534 & $<.05$ & .10 \\
SOA $\times$ T1 Position & 6.989 & $<.05$ & .12 \\
SOA $\times$ Experiment & 2.849 & .098 & \\
Set Size $\times$ T1 Position & 1.380 & .246 & \\
Set Size $\times$ Experiment & 105.400 & $<.001$ & .68 \\
T1 Position $\times$ Experiment & 0.554 & .460 & \\
SOA $\times$ Set Size $\times$ T1 Position & 0.514 & .477 & \\
SOA $\times$ Set Size $\times$ Experiment & 0.510 & .478 & \\
SOA $\times$ T1 Position $\times$ Experiment & 0.414 & .523 & \\
Set Size $\times$ T1 Position $\times$ Experiment & 0.241 & .625 & \\
SOA $\times$ Set Size $\times$ T1 Position $\times$ Experiment & 6.402 & $<.05$ & .12 \\
\hline
\end{tabular}

$N=51 . \mathrm{SOA}=$ stimulus onset asynchrony b

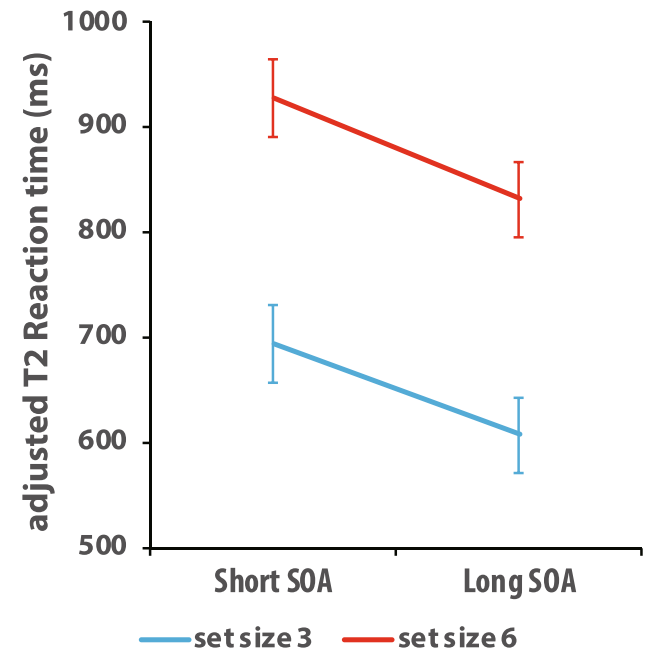

RSVP, there was an additive effect of set size with SOA on adjusted T2 RT. Error bars represent within-subjects $95 \%$ confidence intervals (Cousineau, 2005; Morey, 2008)

investigate this four-way interaction, we split the adjusted T2 RT data into halves (early frame vs. late frame). Subsequently, a three-way mixed ANOVA with SOA and set size as withinsubject factors and experiment as a between-subject factor was separately applied into adjusted T2 RT data of the early frame and adjusted T2 RT data of the late frame. For the early frame of RSVP, there was no significant three-way interaction $(p=.179)$, whereas for the late frame of RSVP, there was a significant three-way interaction, $F(1,49)=5.17, p<.05, \eta_{\mathrm{p}}{ }^{2}$ $=.10$.

Taken together, we confirm that depending on the nature of search process and $\mathrm{T} 1$ position, search performance interacted differently with working memory encoding. Specifically, at the early frame of RSVP, increasing set size of parallel and serial search task had an additive effect with SOA on search $\mathrm{RT}$, whereas at the late frame of RSVP, increasing the set size of parallel search task can only have an underadditive effect with SOA on search RT. Specifically, when visual search was performed in a limited parallel manner, perceptual processing of search items could take place concurrently during working memory encoding only when the T1 appears late. By contrast, when search task requires serial shifting of attention, deployment of visual attention could not be performed during working memory encoding, regardless of when the $\mathrm{T} 1$ was presented in RSVP.

\section{Experiment 4}

Experiment 4 was conducted to further confirm that the interaction between working memory encoding and visual search is modulated by the nature of search process. In this 
experiment, a single group of participants performed the two different search tasks while encoding a letter in working memory.

\section{Method}

\section{Participants}

Fifteen adults (six males, 18-25 years old) with normal or corrected-to-normal vision participated for monetary compensation. To determine the sample size, we ran a power analysis using the data set collected in Experiment 1. It was estimated that an $N$ of 13 should be sufficient to detect a significant underadditive interaction between two factors of interest at the level of .80. The study was approved by the Institutional Review Broad (IRB) at Chungnam National University, and all participants gave written informed consent.

\section{Stimuli and apparatus}

The apparatus was identical to those of Experiment 1. The conjunction search stimuli were identical to those of Experiment 1 (see Fig. 2) and the spatial search stimuli were identical to those of Experiment 3 (see Fig. 7).

\section{Design and procedure}

The details were identical to those of Experiment 1, except for the followings. First, the duration of each frame in RSVP was shortened by $30 \mathrm{~ms}$ compared with the other experiments. For this particular group of participants, the 100-ms frame duration yielded nearly $100 \%$ accuracy for $\mathrm{T} 1$ performance. To ensure that the central processing for working memory encoding is strained, we decided to shorten the duration of each frame in the RSVP. Second, this experiment contained two types of blocks: conjunction search task blocks and spatial configuration search task blocks. Each participant performed 12 blocks of 96 trials (six blocks of conjunction search task and six blocks of spatial configuration search task). Based upon the results of Experiment 1 and Experiment 3, we focused on search data when the T1 was positioned at the late frames. To sum up, the experimental design consisted of a 2 $\times 2 \times 2$ factorial design with SOA (short, long), set size (three, six), and search task (conjunction search task block, spatial configuration search task block) as within-subject factors.

\section{Results and discussion}

Mean accuracies of the $\mathrm{T} 1$ and $\mathrm{T} 2$ responses at the conjunction search block were $91.6 \%$ and $98.3 \%$, respectively and those of the $\mathrm{T} 1$ and $\mathrm{T} 2$ responses at the spatial configuration search block was $89.9 \%$ and $92.7 \%$, respectively (see Table 5). A three-way repeated-measures ANOVA with
SOA (short, long), set size (three, six), and search task (conjunction search task block, spatial configuration search task block) as within-subject factors was applied to T1 and T2 accuracy data. For $\mathrm{T} 1$ accuracy data, there was a significant main effect of SOA, $F(1,14)=10.8, p<.01, \eta_{\mathrm{p}}{ }^{2}=.44$. None of the other main effects or interactions were significant $(p \mathrm{~s}>$ $.30)$. For T2 accuracy data, there was a significant main effect of set size, $F(1,14)=18.04, p<.001, \eta_{\mathrm{p}}^{2}=.56$, and search task, $F(1,14)=10.37, p<.01, \eta_{\mathrm{p}}{ }^{2}=.43$. The two-way interaction between SOA and search task was significant, $F(1,14)$ $=5.42, p<.05, \eta_{\mathrm{p}}{ }^{2}=.28$. The two-way interaction between set size and search task was also significant, $F(1,14)=23.39$, $p<.001, \eta_{\mathrm{p}}{ }^{2}=.63$. None of the other main effects or interactions were significant $(p \mathrm{~s}>.16)$.

To analyze RT data for T2, we adjusted RT on search accuracy due to the significant main effect of set size on search accuracy (see also Experiments 1 and 3). For adjusted T2 RT data, we applied a three-way repeated-measures ANOVA with SOA (short, long), set size (three, six), and search task (conjunction search task block, spatial configuration search task block) as within-subject factors. Importantly, only trials in which the $\mathrm{T} 1$ and $\mathrm{T} 2$ responses were correct were analyzed. This analysis revealed significant main effects of SOA, $F(1$, 14) $=76.03, p<.001, \eta_{\mathrm{p}}{ }^{2}=.84$, set size, $F(1,14)=135.4, p<$ $.001, \eta_{\mathrm{p}}{ }^{2}=.91$, and search task $F(1,14)=89.99, p<.001, \eta_{\mathrm{p}}{ }^{2}$ $=.87$. The two-way interaction between set size and search task was significant, $F(1,14)=76.84, p<.001, \eta_{\mathrm{p}}{ }^{2}=.85$. Importantly, we found a significant three-way interaction, $F(1,14)=4.85, p>.05, \eta_{\mathrm{p}}{ }^{2}=.26$.

To specifically investigate the significant three-way interaction, we split the data into the conjunction search task block and the spatial configuration search task block, and two-way

Table 5 Accuracy (\%) data for Experiment 4

\begin{tabular}{llll}
\hline & & Late frame \\
\cline { 3 - 4 } & & Set Size 3 & Set Size 6 \\
\hline Conjunction search & Task 1 & & \\
& Short SOA & $90.6(6.9)$ & $90.5(5.4)$ \\
& Long SOA & $92.6(4.5)$ & $93.0(4.3)$ \\
& Task 2 & & \\
& Short SOA & $97.9(2.5)$ & $98.2(1.5)$ \\
& Long SOA & $98.5(2.4)$ & $98.4(1.5)$ \\
Spatial configuration search & Task 1 & & \\
& Short SOA & $88.4(8.6)$ & $88.1(7.4)$ \\
& Long SOA & $91.3(4.5)$ & $91.9(5.7)$ \\
& Task 2 & & \\
& Short SOA & $96.1(4.8)$ & $86.4(10.5)$ \\
& Long SOA & $97.7(5.4)$ & $90.6(8.4)$ \\
\hline
\end{tabular}

Note. Standard error in parentheses. SOA = stimulus onset asynchrony 
ANOVAs were applied for each search task block, with SOA and set size as factors. Under the conjunction search task block, there was a significant main effect of SOA, $F(1,14)$ $=161.1, p<.001, \eta_{\mathrm{p}}{ }^{2}=.92$, and set size, $F(1,14)=88.1, p<$ $.001, \eta_{\mathrm{p}}^{2}=.86$. Importantly, this test revealed a significant underadditive interaction between SOA and set size (see Fig. 9 a), $F(1,14)=6.13, p<.05, \eta_{\mathrm{p}}{ }^{2}=.30$. A subsequent pairwise $t$ test showed that the magnitude of set-size effect was significantly smaller at the short SOA $(29 \mathrm{~ms})$ than at the long SOA (48 ms), $t(14)=2.48, p<.05$, Cohen's $d=0.87$. Under the spatial configuration search task block, there was a significant main effect of SOA, $F(1,14)=24.92, p<.001, \eta_{\mathrm{p}}{ }^{2}=.64$, and set size, $F(1,14)=106.8, p<.001, \eta_{\mathrm{p}}{ }^{2}=.88$. Importantly, the interactions between SOA and set size were not significant $(p$ $>.10$; see Fig. 9b).

Taken together, we replicated the results of Experiment 1 and Experiment 3 using a within-subject design. Specifically, when the search is presumed to be parallel, we found an underadditive interaction between SOA and set size. This result implies that the perceptual processing of the stimuli could be carried out simultaneously during the working memory encoding. By contrast, when the search is serial, we found that increasing search set size had an additive effect on search RT with SOA, postponing perceptual processing of search items until the T1 encoding is finished.

\section{General discussion}

The present study investigated the interplay between central attention needed for working memory encoding and response selection and visual attention deployed for visual search. Specifically, in Experiments 1 and 2, participants performed the task of working memory encoding or speeded response

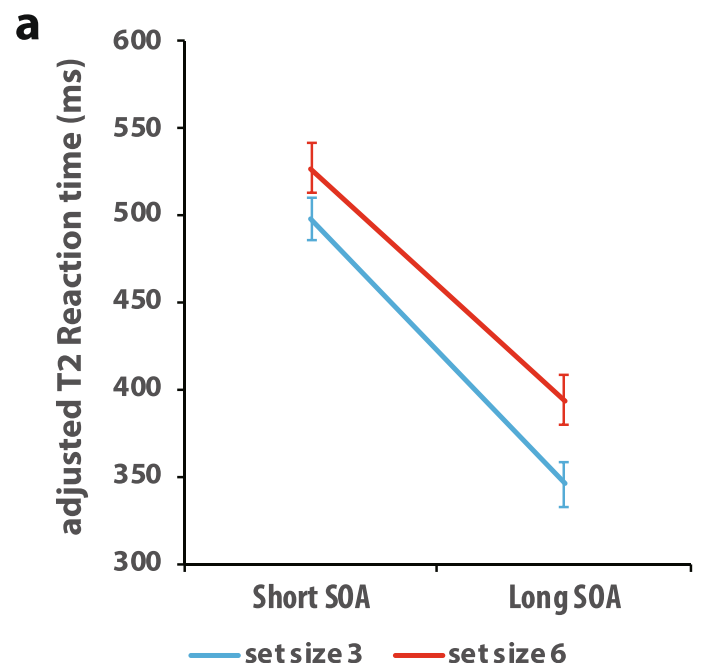

Fig. 9 Result of Experiment 4. a Under the conjunction search task block, there was a significant underadditive interaction between stimulus onset asynchrony (SOA) and set size. b Under the spatial selection task, followed by the conjunction search task. We found the significant underadditive interaction of set size on search RT with SOA, implying that perceptual processing of conjunction search carried out simultaneously when the two tasks were presented in a close temporal proximity. In Experiment 3, we used the same paradigm with Experiment 1, replacing the conjunction search task with a spatial configuration search task. In this case, we found that increasing search set size had an additive effect on search RT with SOA. This result implies that perceptual processing in spatial configuration search display did not take place concurrently during the encoding of T1 into working memory. This result is consistent with the result from Ghorashi et al. (2007), suggesting that visual search is postponed until encoding of $\mathrm{T} 1$ into working memory is completed. Furthermore, these results were replicated in Experiment 4, where the search type was manipulated within a single group of participants.

To account for these results, we suggest that these results should be because the tasks of searching for a conjunction target and a target defined by spatial configuration are performed in different manners. Alternatively, the difference in tasks employed to strain central attention, rather than the difference in visual search tasks, might have caused differential results. Specifically, in Experiment 2, we used the PRP paradigm to replicate the results from Han (2017a) and Reimer and colleagues (Reimer \& Schubert, 2019; Reimer et al., 2015; Reimer et al., 2016), whereas the AB paradigm was used in Experiment 3 and in Ghorashi et al. (2007). However, there was behavioral and neuroscientific evidence suggesting that the $\mathrm{AB}$ and PRP are commonly associated with the capacity-limited central stage (Jolicoeur, 1998, 1999; Jolicoeur \& Dell'Acqua, 1998; Ruthruff \& Pashler, 2001; Tombu et al., 2011). In line with this, applying a three-way mixed ANOVA with SOA and set size as within-

b

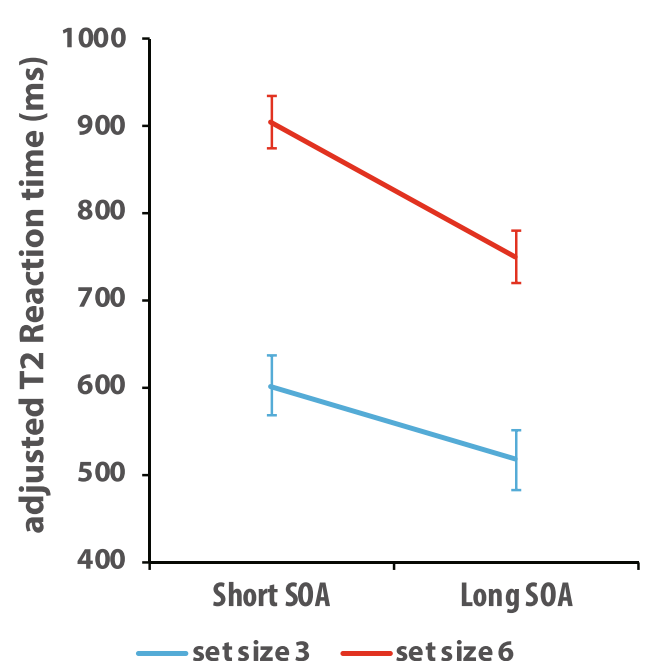

configuration search task block, there was an additive effect of set size with SOA on T2 reaction time (RT). Error bars represent within-subjects 95\% confidence intervals (Cousineau, 2005; Morey, 2008) 
subject factors and experiment (Experiment 1 vs. Experiment 2) as a between-subject factor, we also found the similar pattern of results between Experiment 1 and Experiment $2(p=$ $.582)$.

Thus, we suggest that the difference in visual search is a primary factor responsible for the controversy. Specifically, it is well known that spatial configuration search is performed via serial shifting of attention (Bricolo et al., 2002; Kwak et al., 1991; Wolfe et al., 1989; Woodman \& Luck, 2003). Namely, to locate a target defined by spatial configuration, the capacity-limited attentional resources should be serially allocated to each search stimulus. Hence, the demand for serial shifting of attention should increase as the number of search item increase. By contrast, how the conjunction search is performed is relatively unclear. Originally, Treisman and Gelade (1980) argued that the conjunction search is performed by serial shifting of attention. However, it is also possible that a limited amount of attentional resource is shared by multiple conjunction stimuli. In this case, search proceeds in a parallel manner (Sung, 2008; Townsend, 1971, 1972). In line with this, a group of researchers showed evidence that the process of searching for a conjunction item proceeds in a parallel manner by investigating the neuronal firing rates of monkeys (Bichot et al., 2005).

Furthermore, human fMRI studies showed that different regions were activated for different search tasks (spatial configuration task vs. conjunction search task). In the study of Anderson et al. (2007), when the participants searched for a $T$ among $L \mathrm{~s}$, the region of inferior and middle frontal cortex were activated as the search set size increases. By contrast, these regions were not found during the conjunction search task (Leonards, Sunaert, Van Hecke, \& Orban, 2000). Importantly, under this kind of limited parallel search, demand for serial shifting of attention remained constant as the number of search items increase. While we do not provide direct evidence that the conjunction search in the present experiment proceeded in a limited parallel, considering previous neuroscientific and behavioral evidence, the conjunction search seems to be performed differentially from the spatial configuration search. Future research regarding this issue would also be fruitful.

Taken together, what matters here is whether the demand for serial shifting of attention would increase as the number of search set size increase. Specifically, neurophysiological studies (Brisson \& Jolicoeur, 2007a, 2007b; Lien, Croswaite, \& Ruthruff, 2011, Experiments 3 and 4) showed that when participants allocate focal attention to locate the target (Task 2), following a tone discrimination task (Task 1), an N2posterior-contralateral component (N2pc) amplitude is attenuated as the SOA between two tasks is reduced. Given the $\mathrm{N} 2 \mathrm{pc}$ is an index of deployment of visuospatial attention toward a target location (Woodman \& Luck, 1999), this result implied that taxing the central attention of a task interfered with the deployment of focal attention for the other concurrent task. Based upon this, Brisson and Jolicoeur (2007a) claimed that central attention was involved in the deployment of focal attention. In line with this, Han (2017a) suggested that the demand for serial shifting of focal attention determines the involvement of central attention in visual search.

Based upon this, we were able to predict that if the demand for focal attention increases as the number of search items increases, concurrent central processing of another task should impair the search process controlled by central attention. Thus, when participants search for a spatial configuration target, the demand for focal attention increases as search items increase because spatial configuration search task requires serial shifting of focal attention. By contrast, when participants search for a conjunction target, the demand for focal attention is invariant across all set sizes because the conjunction search task is known to be performed in a limited parallel manner. Thus, we suppose that the results of Experiment 3 and Ghorashi et al. (2007) were due to a search task, spatial configuration search, requiring increased demand for serial shifting of focal attention with increased set size.

Hence, we hypothesized that when visual search is performed in a limited parallel manner, such that increased set size does not require increased demand of serial shifting of focal attention, the perceptual processing of search stimuli should be able to carry out concurrently during central processes, such as response selection and working memory encoding. To test this hypothesis, we used the conjunction search task, similar to the one used in Han (2017a), as the second task under the $\mathrm{AB}$ (Experiment 1) and PRP (Experiment 2) paradigm. As we predicted, unlike in Experiment 3 and the study by Ghorashi et al. (2007), using spatial configuration search task as the second task, we found that perceptual analysis of conjunction search could proceed concurrently both during working memory encoding and response selection.

Furthermore, we also found that the serial position of $\mathrm{T} 1$ in an RSVP affects the interaction of search performance and working memory encoding. Following the suggestion of an anonymous reviewer, we divided our T2 RT data into halves, depending on the serial position of T1 in the RSVP (early frame vs. late frame). In Experiments 1 and 3, we added the $\mathrm{T} 1$ position as within-subject factor and ran a three-way ANOVA. This analysis showed that visual search cannot take place concurrently during working memory encoding when the T1 appears early, regardless of whether the search is parallel or serial. To explain this result, we suggest that the attentional awakening phenomenon (Ariga \& Yokosawa, 2008) interfered with the deployment of visual attention, even when the search is parallel.

According to the study by Ariga and Yokosawa (2008), when the target was presented early in the RSVP, the target performance was significantly reduced than when the target 
was presented late. This attentional awakening (AA) is suggested to be caused by insufficient preparation for allocating temporal attention to the unexpected target in the RSVP (Holcombe et al., 2001). That is, visual system needed to allocate visual attention is gradually prepared as the sequence of the RSVP progressed. Based upon this, we suggest that the system for deployment of visual attention to locate a conjunction search target was not configured at the early frame of RSVP, either. Hence, the deployment of visual attention was impaired by working memory encoding, yielding an additive effect of SOA and set size on search RT. By contrast, when the system was sufficiently configured because $\mathrm{T} 1$ was presented sufficiently late, the deployment of visual attention took place concurrently during the central processing. However, importantly, when the search was serial, the deployment of visual attention was interfered with by the central processing, regardless of whether the visual system is sufficiently configured or not.

Finally, to provide further compelling evidence that visual search differently interacts with working memory encoding, depending on the search nature, we conducted an experiment that included a manipulation of search task within a single group of participants. Again, we found an underadditive interaction under the conjunction search, whereas an additive effect was found under the spatial configuration search task block.

To conclude, the present study suggests that whether the perceptual process of visual search stimuli can carry out simultaneously with central processes for another task depends on the nature of visual search. Specifically, when visual search task is performed in a parallel manner, the perceptual identification process of the search stimuli can carry out concurrently during the central processing of another stimulus. By contrast, when the processing of multiple search stimuli should be done in a serial manner, visual search should be postponed until a concurrent central process is finished. Furthermore, this kind of interplay of central process and visual search performance is modulated by the attentional awakening effect.

Acknowledgements This work was supported by the Chungnam National University research fund.

Open practice statement All the data and experimental and analysis codes are available upon reasonable requests.

\section{References}

Anderson, E. J., Mannan, S. K., Husain, M., Rees, G., Sumner, P., Mort, D. J., ... Kennard, C. (2007). Involvement of prefrontal cortex in visual search. Experimental Brain Research, 180(2), 289-302. doi: https://doi.org/10.1007/s00221-007-0860-0

Ariga, A., \& Yokosawa, K. (2008). Attentional awakening: Gradual modulation of temporal attention in rapid serial visual presentation. Psychological Research, 72(2), 192-202. doi:https://doi.org/10. 1007/s00426-006-0100-4
Bae, E., Jung, S., \& Han, S. W. (2018). The perceptual enhancement by spatial attention is impaired during the attentional blink. Acta Psychologica, 190, 150-158. doi:https://doi.org/10.1016/j.actpsy. 2018.08.005

Bichot, N. P., Rossi, A. F., \& Desimone, R. (2005). Parallel and serial neural mechanisms for visual search in macaque area V4. Science, 308(5721), 529-534. doi:https://doi.org/10.1126/science.1109676

Bouvier, S., \& Treisman, A. (2010). Visual feature binding requires reentry. Psychological Science, 21(2), 200-204. doi:https://doi.org/ 10.1177/0956797609357858

Bricolo, E., Gianesini, T., Fanini, A., Bundesen, C., \& Chelazzi, L. (2002). Serial attention mechanisms in visual search: A direct behavioral demonstration. Journal of Cognitive Neuroscience, 14(7), 980-993. doi:https://doi.org/10.1162/089892902320474454

Brisson, B., \& Jolicoeur, P. (2007a). Electrophysiological evidence of central interference in the control of visuospatial attention. Psychonomic Bulletin \& Review, 14(1), 126-132. doi:https://doi. org/10.3758/Bf03194039

Brisson, B., \& Jolicoeur, P. (2007b). A psychological refractory period in access to visual short-term memory and the deployment of visualspatial attention: Multitasking processing deficits revealed by eventrelated potentials. Psychophysiology, 44(2), 323-333. doi:https:// doi.org/10.1111/j.1469-8986.2007.00503.x

Chun, M. M., \& Potter, M. C. (1995). A two-stage model for multiple target detection in rapid serial visual presentation. Journal of Experimental Psychology: Human Perception \& Performance, 21(1), 109-127. Retrieved from https://www.ncbi.nlm.nih.gov/ pubmed/7707027

Cousineau, D. (2005). Confidence intervals in within-subject designs: A simpler solution to Loftus and Masson's method. Tutorials in Quantitative Methods for Psychology, 1(1), 42-45. doi:https://doi. org/10.20982/tqmp.01.1.p042

Ghorashi, S. M., Smilek, D., \& Di Lollo, V. (2007). Visual search is postponed during the attentional blink until the system is suitably reconfigured. Journal of Experimental Psychology: Human Perception \& Performance, 33(1), 124-136. doi:https://doi.org/10. 1037/0096-1523.33.1.124

Graham, K. S., Scahill, V. L., Hornberger, M., Barense, M. D., Lee, A. C., Bussey, T. J., \& Saksida, L. M. (2006). Abnormal categorization and perceptual learning in patients with hippocampal damage. Journal of Neuroscience, 26(29), 7547-7554. doi:https://doi.org/ 10.1523/JNEUROSCI.1535-06.2006

Han, S. W. (2017a). The involvement of central attention in visual search is determined by task demands. Attention, Perception, \& Psychophysics, 79(3), 726-737. doi:https://doi.org/10.3758/ s13414-017-1278-9

Han, S. W. (2017b). Search for capacity-limited and super-capacity search. Experimental Psychology, 64(3), 149-158. doi:https://doi. org/10.1027/1618-3169/a000356

Han, S. W., \& Marois, R. (2013). The source of dual-task limitations: Serial or parallel processing of multiple response selections? Attention, Perception, \& Psychophysics, 75(7), 1395-1405. doi: https://doi.org/10.3758/s13414-013-0513-2

Holcombe, A. O., Kanwisher, N., \& Treisman, A. (2001). The midstream order deficit. Perception \& Psychophysics, 63(2), 322-329. doi: https://doi.org/10.3758/bf03194472

Huang, L., \& Pashler, H. (2005). Attention capacity and task difficulty in visual search. Cognition, 94(3), B101-B111.

Jolicoeur, P. (1998). Modulation of the attentional blink by on-line response selection: Evidence from speeded and unspeeded task1 decisions. Memory \& Cognition, 26(5), 1014-1032. Retrieved from https://www.ncbi.nlm.nih.gov/pubmed/9796233

Jolicoeur, P. (1999). Concurrent response-selection demands modulate the attentional blink. Journal of Experimental Psychology: Human Perception \& Performance, 25(4), 1097-1113. doi:https://doi.org/ 10.1037/0096-1523.25.4.1097 
Jolicoeur, P., \& Dell'Acqua, R. (1998). The demonstration of short-term consolidation. Cognitive Psychology, 36(2), 138-202. doi:https:// doi.org/10.1006/cogp.1998.0684

Jolicoeur, P., \& Dell'Acqua, R. (1999). Attentional and structural constraints on visual encoding. Psychological Research/Psychologische Forschung, 62(2/3), 154-164. doi:https://doi.org/10.1007/ s004260050048

Klemen, J., Verbruggen, F., Skelton, C., \& Chambers, C. D. (2011). Enhancement of perceptual representations by endogenous attention biases competition in response selection. Attention, Perception, \& Psychophysics, 73(8), 2514-2527. doi:https://doi.org/10.3758/ s13414-011-0188-5

Kwak, H. W., Dagenbach, D., \& Egeth, H. (1991). Further evidence for a time-independent shift of the focus of attention. Perception \& Psychophysics, 49(5), 473-480. doi:https://doi.org/10.3758/ Bf03212181

Lagroix, H. E. P., Grubert, A., Spalek, T. M., Di Lollo, V., \& Eimer, M. (2015). Visual search is postponed during the period of the AB: An event-related potential study. Psychophysiology, 52(8), 1031-1038. doi:https://doi.org/10.1111/psyp.12435

Leonards, U., Sunaert, S., Van Hecke, P., \& Orban, G. A. (2000). Attention mechanisms in visual search-An fMRI study. Journal of Cognitive Neuroscience, 12(Suppl. 2), 61-75. doi:https://doi.org/ $10.1162 / 089892900564073$

Lien, M. C., Croswaite, K., \& Ruthruff, E. (2011). Controlling spatial attention without central attentional resources: Evidence from eventrelated potentials. Visual Cognition, 19(1), 37-78. doi:https://doi. org/10.1080/13506285.2010.491643

Morey, R. D. (2008). Confidence intervals from nomalized data: A comection to Cousineau (2005). Tutorials in Quantitative Methods for Psychology, 4(2), 61-64. doi:https:/doi. org/10.20982tamp.04.2.p061

Pashler, H. (1984). Processing stages in overlapping tasks: Evidence for a central bottleneck. Journal of Experimental Psychology: Human Perception \& Performance, 10(3), 358-377. Retrieved from https://www.ncbi.nlm.nih.gov/pubmed/6242412

Pashler, H. (1994). Dual-task interference in simple tasks-Data and theory. Psychological Bulletin, 116(2), 220-244. doi:https://doi. org/10.1037/0033-2909.116.2.220

Peirce, J. W. (2007). PsychoPy: Psychophysics software in Python. Journal of Neuroscience Methods, 162(1/2), 8-13. doi:https://doi. org/10.1016/j.jneumeth.2006.11.017

Raymond, J. E., Shapiro, K. L., \& Arnell, K. M. (1992). Temporary suppression of visual processing in an RSVP task: An attentional blink. Journal of Experimental Psychology: Human Perception \& Performance, 18(3), 849-860. doi:https://doi.org/10.1037//00961523.18.3.849

Reimer, C. B., \& Schubert, T. (2019). More insight into the interplay of response selection and visual attention in dual-tasks: Masked visual search and response selection are performed in parallel. Psychological Research, 83(3), 459-475. doi:https://doi.org/10. 1007/s00426-017-0906-2

Reimer, C. B., Strobach, T., Frensch, P. A., \& Schubert, T. (2015). Are processing limitations of visual attention and response selection subject to the same bottleneck in dual-tasks? Attention, Perception, \& Psychophysics, 77(4), 1052-1069. doi:https://doi.org/10.3758/ s13414-015-0874-9

Reimer, C. B., Strobach, T., \& Schubert, T. (2016). Concurrent deployment of visual attention and response selection bottleneck in a dualtask: Electrophysiological and behavioural evidence. Quarterly Journal of Experimental Psychology, 70(12), 2460-2477. doi: https://doi.org/10.1080/17470218.2016.1245348

Romei, V., Driver, J., Schyns, P. G., \& Thut, G. (2011). Rhythmic TMS over parietal cortex links distinct brain frequencies to global versus local visual processing. Current Biology, 21(4), 334-337. doi: https://doi.org/10.1016/j.cub.2011.01.035
Ruthruff, E., \& Pashler, H. (2001). Perceptual and central interference in dual-task performance. In K. Shapiro (Ed.), The limits of attention: Temporal constraints in human information processing (pp. 100123). Oxford, England: Oxford University Press. doi:https://doi.org/ 10.1093/acprof:oso/9780198505150.003.0006

Spence, C., Kettenmann, B., Kobal, G., \& McGlone, F. P. (2001). Shared attentional resources for processing visual and chemosensory information. Quarterly Journal of Experimental Psychology, A, 54(3), 775-783. doi:https://doi.org/10.1080/713755985

Sung, K. (2008). Serial and parallel attentive visual searches: Evidence from cumulative distribution functions of response times. Journal of Experimental Psychology: Human Perception \& Performance, 34(6), 1372-1388. doi:https://doi.org/10.1037/a0011852

Tamber-Rosenau, B. J., \& Marois, R. (2016). Central attention is serial, but midlevel and peripheral attention are parallel-A hypothesis. Attention, Perception, \& Psychophysics, 78(7), 1874-1888. doi: https://doi.org/10.3758/s13414-016-1171-y

Tombu, M. N., \& Jolicœur, P. (2003). A central capacity sharing model of dual-task performance. Journal of Experimental Psychology: Human Perception \& Performance, 29(1), 3. doi:https://doi.org/ 10.1037//0096-1523.29.1.3

Tombu, M. N., \& Jolicœur, P. (2005). Testing the predictions of the central capacity sharing model. Journal of Experimental Psychology: Human Perception \& Performance, 31(4), 790. doi: https://doi.org/10.1037/0096-1523.31.4.790

Tombu, M. N., Asplund, C. L., Dux, P. E., Godwin, D., Martin, J. W., \& Marois, R. (2011). A unified attentional bottleneck in the human brain. Proceedings of the National Academy of Sciences of the United States of America, 108(33), 13426-13431. doi:https://doi. org/10.1073/pnas. 1103583108

Townsend, J. T. (1971). A note on the identifiability of parallel and serial processes. Perception \& Psychophysics, 10(3), 161-163. doi:https:// doi.org/10.3758/BF03205778

Townsend, J. T. (1972). Some results concerning the identifiability of parallel and serial processes. British Journal of Mathematical and Statistical Psychology, 25(2), 168-199. doi:https://doi.org/10.1111/ j.2044-8317.1972.tb00490.x

Townsend, J. T., \& Ashby, F. G. (1983). Stochastic modeling of elementary psychological processesl Cambridge, England: Cambridge University Press Archive.

Treisman, A. M., \& Gelade, G. (1980). A feature-integration theory of attention. Cognitive Psychology, 12(1), 97-136. Retrieved from https://www.ncbi.nlm.nih.gov/pubmed/7351125

Welford, A. T. (1952). The 'psychological refractory period'and the timing of high-speed performance: A review and a theory. British Journal of Psychology: General Section, 43(1), 2-19. doi:https:// doi.org/10.1111/j.2044-8295.1952.tb00322.x

Wolfe, J. M. (1998). What can 1 million trials tell us about visual search? Psychological Science, 9(1), 33-39. doi:https://doi.org/10.1111/ 1467-9280.00006

Wolfe, J. M., Cave, K. R., \& Franzel, S. L. (1989). Guided search: An alternative to the feature integration model for visual search. Journal of Experimental Psychology: Human Perception \& Performance, 15(3), 419-433. doi:https://doi.org/10.1037/0096-1523.15.3.419

Woodman, G. F., \& Luck, S. J. (1999). Electrophysiological measurement of rapid shifts of attention during visual search. Nature, 400(6747), 867-869. doi:https://doi.org/10.1038/23698

Woodman, G. F., \& Luck, S. J. (2003). Serial deployment of attention during visual search. Journal of Experimental Psychology: Human Perception \& Performance, 29(1), 121-138. doi:https://doi.org/10. 1037/0096-1523.29.1.121

Publisher's note Springer Nature remains neutral with regard to jurisdictional claims in published maps and institutional affiliations. 